\title{
One-pot synthesis of cyanohydrin derivatives from alkyl bromides via incorporation of two one-carbon components by consecutive radical/ionic reactions
}

Shuhei Sumino, Akira Fusano, Hiroyuki Okai, Takahide Fukuyama and Ilhyong Ryu*

\author{
Letter \\ Address: \\ Department of Chemistry, Graduate School of Science, Osaka \\ Prefecture University, Sakai, Osaka 599-8531, Japan \\ Email: \\ Ilhyong Ryu* - ryu@c.s.osakafu-u.ac.jp \\ * Corresponding author \\ Keywords: \\ alkyl bromide; carbon monoxide; cyanohydrin; ethyl cyanoformate; \\ multicomponent; radical reaction
}

Beilstein J. Org. Chem. 2014, 10, 150-154.

doi:10.3762/bjoc. 10.12

Received: 30 September 2013

Accepted: 10 December 2013

Published: 14 January 2014

This article is part of the Thematic Series "Multicomponent reactions II".

Guest Editor: T. J. J. Müller

(c) 2014 Sumino et al; licensee Beilstein-Institut.

License and terms: see end of document.

\section{Abstract}

The consecutive radical/ionic reaction consisting of radical formylation of alkyl bromides and nucleophilic addition of a cyanide ion was investigated, which gave moderate to good yields of cyanohydrin derivatives in one-pot.

\section{Introduction}

Radical carbonylation reactions have been recognized as a versatile tool for the synthesis of a wide variety of carbonyl compounds [1-4]. In 1990, we demonstrated that aldehydes can be prepared from alkyl or aromatic halides and CO under typical radical chain reaction conditions using tributyltin hydride and AIBN [5,6]. Under the reaction conditions where a catalytic amount of fluorous tin hydride and an excess amount of sodium cyanoborohydride were used, initially formed aldehydes can be converted into hydroxymethylated compounds in one-pot [7-9], since borohydride acts not only as the reagent for the regeneration of tin hydride [10-13] but also as the reagent for aldehyde reduction. Later on we found that borohydride reagents can also serve as radical mediator delivering hydrogen to the radical centre [14], thus we developed a hydroxymethylation method using $\mathrm{Bu}_{4} \mathrm{NBH}_{4}$ and a radical initiator [15-17]. Recent work in collaboration with Dennis Curran has revealed that, with the use of NHC-borane [18], hydroxymethylation of aromatic iodides can be attained [19]. All these reactions consist of the combination of radical formylation with $\mathrm{CO}$ and ionic hydride reduction by hydride reagents (Scheme 1, reaction 1). During the course of our study on borohydride-mediated radical hydroxymethylation of alkyl halides with $\mathrm{CO}$, we found that cyanohydrin was obtained as a byproduct when $\mathrm{Bu}_{4} \mathrm{NBH}_{3} \mathrm{CN}$ was used as a radical mediator [15], which led us to investigate the one-pot synthesis of cyanohydrins based on radical formylation. Thus, we thought that the two step radical/ionic reactions 
Our previous work: one-pot synthesis of one-carbon homologated alcohols

$$
\begin{aligned}
& \mathrm{R}-\mathrm{X} \longrightarrow \mathrm{R}^{\cdot} \stackrel{\mathrm{CO}}{\longrightarrow} \mathrm{R}^{\mathrm{I}} \cdot \stackrel{\mathrm{MH}}{\longrightarrow} \mathrm{R}_{\mathrm{H}}^{\stackrel{\mathrm{O}}{\mathrm{N}} \stackrel{\mathrm{H}^{-}}{\longrightarrow} \mathrm{R}^{\prime}} \\
& \left(\mathrm{C}_{6} \mathrm{~F}_{13} \mathrm{CH}_{2} \mathrm{CH}_{2}\right)_{3} \mathrm{SnH} \quad \mathrm{NaBH}_{3} \mathrm{CN} \\
& \mathrm{Bu}_{4} \mathrm{NBH}_{4} \quad \mathrm{Bu}_{4} \mathrm{NBH}_{4} \\
& \mathrm{Bu}_{4} \mathrm{NBH}_{3} \mathrm{CN} \quad \mathrm{Bu}_{4} \mathrm{NBH}_{3} \mathrm{CN}
\end{aligned}
$$

This work: one-pot synthesis of cyanohydrin derivatives

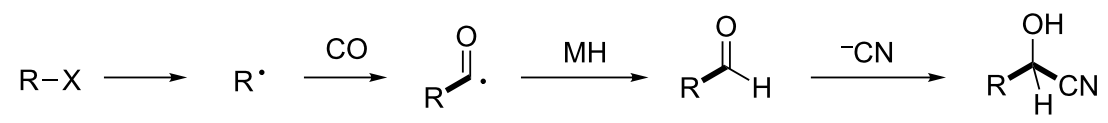

Scheme 1: Sequential radical formylation and derivatization.

can be extended to the consecutive $\mathrm{C}-\mathrm{C}$ bond forming reactions.

Cyanohydrins are important subunits frequently found in biologically active compounds and are also versatile building blocks for further synthetic transformations [20,21]. The common method to obtain cyanohydrins is the reaction of aldehydes with a cyanide sources such as TMSCN $[22,23]$, ethyl cyanoformate [24-26] or acyl cyanide [27,28]. We provide here an efficient one-pot method for the synthesis of cyanohydrin derivatives via consecutive radical/ionic $\mathrm{C}-\mathrm{C}$ bond forming reaction of alkyl bromides, $\mathrm{CO}$ and ethyl cyanoformate (Scheme 1, reaction 2).

\section{Results and Discussion}

We examined AIBN-induced radical formylation of 1-bromooctane (1a) with $\mathrm{Bu}_{3} \mathrm{SnH}$ under $80 \mathrm{~atm}$ of $\mathrm{CO}$ pressure in the presence of a cyanide source (Scheme 2). Under the employed conditions, the reaction using TMSCN (2a') was slow, which gave $16 \%$ of $\mathbf{3} \mathbf{a}^{\prime}$ and $51 \%$ of nonanal. The use of AcCN (2a") also gave $3 \mathrm{a}^{\prime \prime}$ but only in $12 \%$ yield. However, when ethyl cyanoformate (2a) was used together with $\mathrm{Et}_{3} \mathrm{~N}$ [29], the cyanohydrin 3a was obtained in $62 \%$ yield. When we used higher $\mathrm{CO}$ pressure such as $120 \mathrm{~atm}$, the yield of $\mathbf{3 a}$ increased to $79 \%$.

We examined various alkyl bromides $\mathbf{1}$ in the present radical/ ionic three-component coupling reaction (Table 1). Primary alkyl bromides $\mathbf{1 b}-\mathbf{e}$ containing a chlorine atom, an ester group, a cyano group, or a phenyl group worked well to give the corresponding cyanohydrin derivatives $\mathbf{3 b}-\mathbf{e}$ in good yields (Table 1, entries 2-5). The reaction of secondary and tertiary alkyl bromides $\mathbf{1 f}-\mathbf{i}$ also proceeded well to give the corresponding cyanohydrins $\mathbf{3 f}-\mathbf{i}$ in good yields (Table 1, entries 6-9). The reaction using cyclopropylmethyl bromide (1j) afforded the lowest yield of cyanohydrin $\mathbf{3} \mathbf{j}$, which possessed an olefin structure arising from the ring-opening of a cyclopropylcarbinyl radical (Table 1, entry 10) [30,31].

\section{Conclusion}

In summary, we have demonstrated a three-component coupling reaction comprising alkyl bromides $\mathbf{1}, \mathrm{CO}$ and ethyl cyanoformate (2a) in the presence of $\mathrm{Bu}_{3} \mathrm{SnH}, \mathrm{AIBN}$, and $\mathrm{Et}_{3} \mathrm{~N}$, which

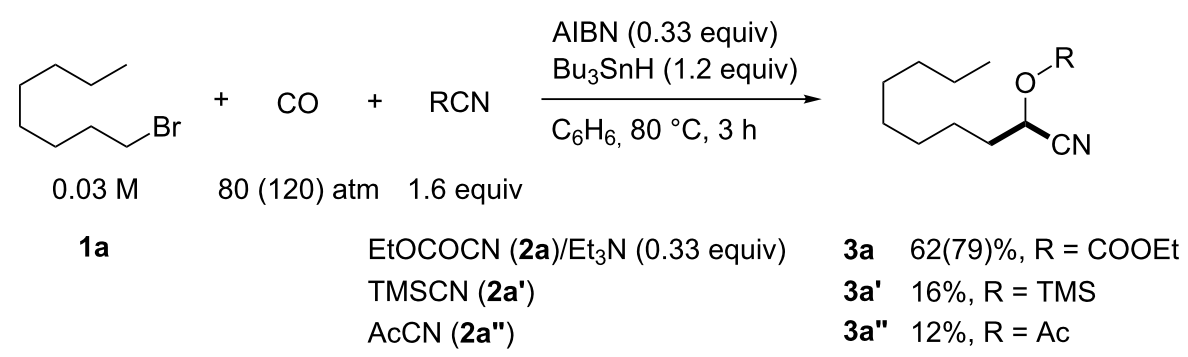

Scheme 2: Examination of cyanide source. 
Table 1: Three-component coupling reaction leading to cyanohydrin derivatives.

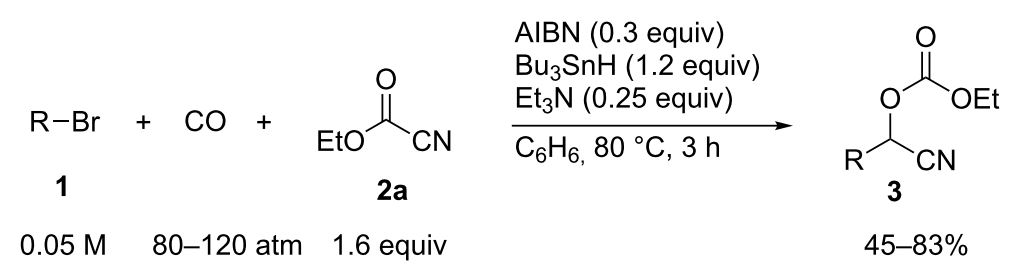

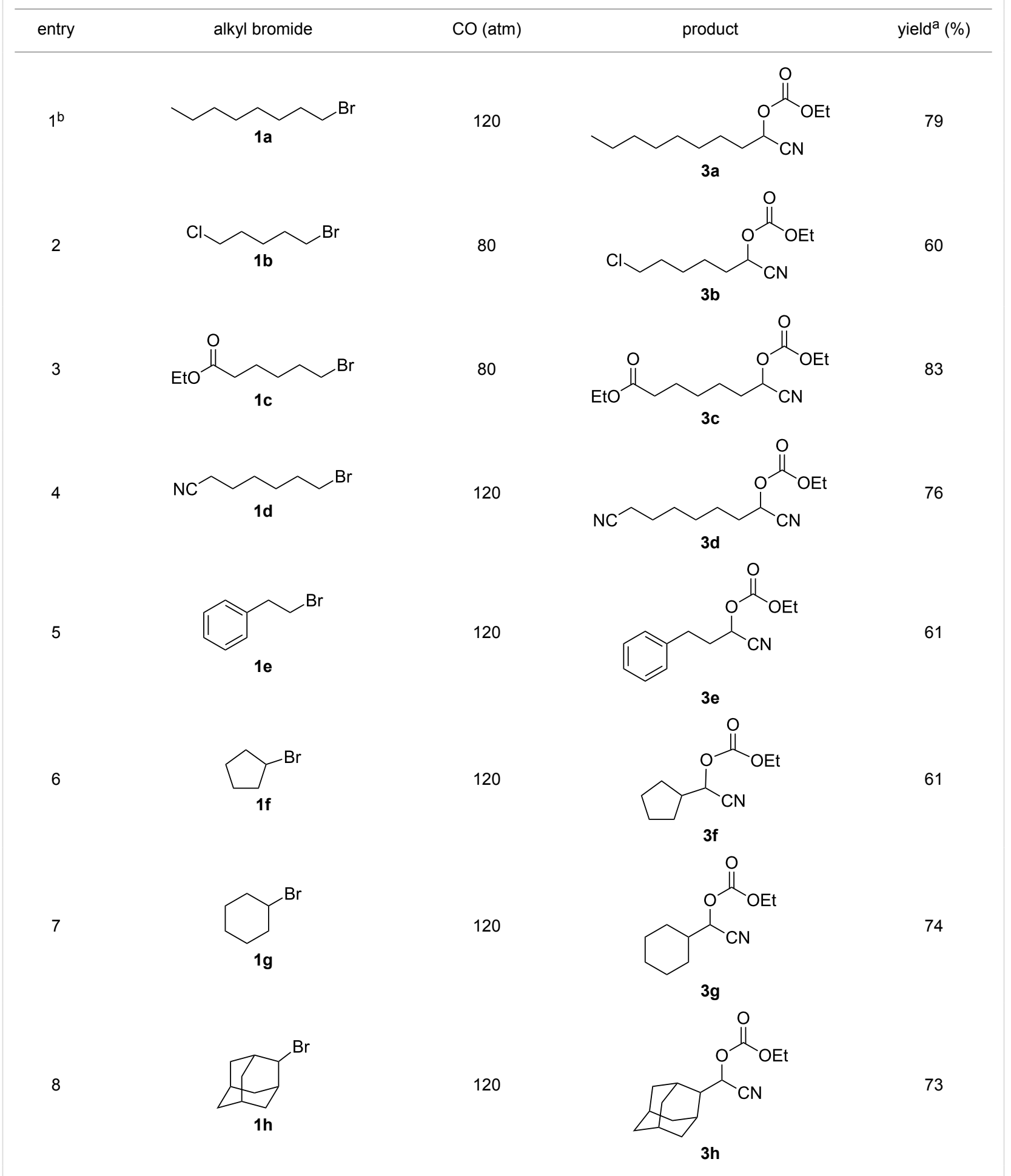


Table 1: Three-component coupling reaction leading to cyanohydrin derivatives. (continued)

9

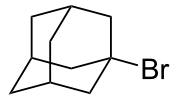

$1 \mathrm{i}$

10

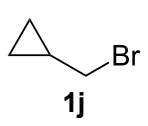

110

110<smiles>CCOC(=O)OC(C#N)C12CC3CC(CC(C3)C1)C2</smiles>

$3 \mathbf{i}$<smiles>C=CCCC(C#N)OC(=O)OCC</smiles>

3j

alsolated yield after flash chromatography on $\mathrm{SiO}_{2} \cdot{ }^{\mathrm{b}} 0.03 \mathrm{M}$.

gave moderate to good yields of cyanohydrin derivatives 3 . This protocol represents a one-pot method [32,33] based on radical carbonylation and ionic cyanation.

\section{Experimental}

Typical procedure for radical/ionic three-component coupling reaction leading to cyanohydrin derivatives 1-cyanononyl ethyl carbonate (3a) [34] (Table 1, entry 1): A mixture of 1-bromooctane (1a, $96.6 \mathrm{mg}, 0.5 \mathrm{mmol}$ ), ethyl cyanoformate (2a, $79.3 \mathrm{mg}, 0.8 \mathrm{mmol})$, tributyltin hydride $(174.6 \mathrm{mg}, 0.6 \mathrm{mmol})$, triethylamine (13.2 mg, $0.13 \mathrm{mmol}$ ), and AIBN (24.6 mg, $0.15 \mathrm{mmol})$ in $\mathrm{C}_{6} \mathrm{H}_{6}(17 \mathrm{~mL})$ were placed in a $100 \mathrm{~mL}$ stainless steel autoclave. The reaction mixture was degassed 3 times with $10 \mathrm{~atm}$ of $\mathrm{CO}$ and charged with $90 \mathrm{~atm}$ of $\mathrm{CO}$ at $-40{ }^{\circ} \mathrm{C}$ (MeCN-dry ice bath). Then the autoclave was allowed to warm to room temperature, which caused the pressure gauge to indicate $120 \mathrm{~atm}$. Then the reaction was conducted at $80^{\circ} \mathrm{C}$ for $3 \mathrm{~h}$. After cooling to room temperature, the reaction mixture was concentrated and purified by silica gel flash chromatography (hexane/EtOAc 97:3) to afford 3a (95.3 mg, 79\%). ${ }^{1} \mathrm{H}$ NMR $\left(\mathrm{CDCl}_{3}, 500 \mathrm{MHz}\right) \delta 5.18(\mathrm{t}, J=6.8 \mathrm{~Hz}, 1 \mathrm{H}), 4.4-4.2(\mathrm{~m}, 2 \mathrm{H})$, $2.0-1.9(\mathrm{~m}, 2 \mathrm{H}), 1.6-1.5(\mathrm{~m}, 2 \mathrm{H}), 1.4-1.2(\mathrm{~m}, 13 \mathrm{H}), 0.88(\mathrm{t}, J=$ $6.9 \mathrm{~Hz}, 3 \mathrm{H}) ;{ }^{13} \mathrm{C} \mathrm{NMR}\left(\mathrm{CDCl}_{3}, 125 \mathrm{MHz}\right) \delta 153.56,116.51$, $65.27,64.66,32.31,31.68,29.12,28.99,28.71,24.34,22.53$, $14.05,13.93$.

\section{Acknowledgements}

We acknowledge a Grant-in-Aid for Scientific Research on Innovative Areas (No. 2105) from the Ministry of Education, Culture, Sports, and Technology (MEXT), Japan.

\section{References}

1. Ryu, I.; Sonoda, N. Angew. Chem., Int. Ed. Engl. 1996, 35, 1050. doi:10.1002/anie.199610501

2. Ryu, I.; Sonoda, N.; Curran, D. P. Chem. Rev. 1996, 96, 177. doi:10.1021/cr9400626

3. Chatgilialoglu, C.; Crich, D.; Komatsu, M.; Ryu, I. Chem. Rev. 1999, 99, 1991. doi:10.1021/cr9601425

4. Ryu, I. Chem. Soc. Rev. 2001, 30, 16. doi:10.1039/a904591k
5. Ryu, I.; Kusano, K.; Ogawa, A.; Kambe, N.; Sonoda, N. J. Am. Chem. Soc. 1990, 112, 1295. doi:10.1021/ja00159a088

6. Ryu, I.; Kusano, K.; Masumi, N.; Yamazaki, H.; Ogawa, A.; Sonoda, N. Tetrahedron Lett. 1990, 31, 6887. doi:10.1016/S0040-4039(00)97198-3

7. Gupta, V.; Kahne, D. Tetrahedron Lett. 1993, 34, 591. doi:10.1016/S0040-4039(00)61627-1

8. Ryu, I.; Niguma, T.; Minakata, S.; Komatsu, M.; Hadida, S.; Curran, D. P. Tetrahedron Lett. 1997, 38, 7883. doi:10.1016/S0040-4039(97)10076-4

9. Matsubara, H.; Yasuda, S.; Sugiyama, H.; Ryu, I.; Fujii, Y.; Kita, K. Tetrahedron 2002, 58, 4071. doi:10.1016/S0040-4020(02)00256-9

10. Corey, E. J.; Suggs, W. J. Org. Chem. 1975, 40, 2554. doi:10.1021/jo00905a039

11. Giese, B.; González-Gómez, J. A.; Witzel, T. Angew. Chem., Int. Ed. Engl. 1984, 23, 69. doi:10.1002/anie.198400691

12. Stork, G.; Sher, P. M. J. Am. Chem. Soc. 1986, 108, 303. doi:10.1021/ja00262a024

13. Curran, D. P.; Hadida, S.; Kim, S.-Y.; Luo, Z. J. Am. Chem. Soc. 1999, 121, 6607. doi:10.1021/ja990069a

14. Ryu, I.; Uehara, S.; Hirao, H.; Fukuyama, T. Org. Lett. 2008, 10, 1005. doi:10.1021/ol7031043

15. Kobayashi, S.; Kawamoto, T.; Uehara, S.; Fukuyama, T.; Ryu, I. Org. Lett. 2010, 12, 1548. doi:10.1021/ol1002847

16. Kobayashi, S.; Kinoshita, T.; Kawamoto, T.; Wada, M.; Kuroda, H.; Masuyama, A.; Ryu, I. J. Org. Chem. 2011, 76, 7096. doi:10.1021/jo201064h

17. Kawamoto, T.; Ryu, I. Chimia 2012, 66, 372.

18. Curran, D. P.; Solovyev, A.; Makhlouf Brahmi, M.; Fensterbank, L.; Malacria, M.; Lacôte, E. Angew. Chem., Int. Ed. 2011, 50, 10294. doi:10.1002/anie.201102717 See for a review on NHC-borane.

19. Kawamoto, T.; Okada, T.; Curran, D. P.; Ryu, I. Org. Lett. 2013, 15, 2144. doi:10.1021/ol4006294

20. Gregory, R. J. H. Chem. Rev. 1999, 99, 3649. doi:10.1021/cr9902906

21. Brunel, J.-M.; Holmes, I. P. Angew. Chem., Int. Ed. 2004, 43, 2752. doi:10.1002/anie.200300604

22. Lidy, W.; Sundermeyer, W. Chem. Ber. 1973, 106, 587. doi:10.1002/cber.19731060224

23. Evans, D. A.; Truesdale, L. K.; Carroll, G. L. J. Chem. Soc., Chem. Commun. 1973, 55. doi:10.1039/c39730000055

24. Poirier, D.; Berthiaume, D.; Boivin, R. P. Synlett 1999, 1423. doi:10.1055/s-1999-2859

25. Berthiaume, D.; Poirier, D. Tetrahedron 2000, 56, 5995. doi:10.1016/S0040-4020(00)00535-4 
26. Tian, S.-K.; Deng, L. J. Am. Chem. Soc. 2001, 123, 6195. doi:10.1021/ja010690m

27. Hoffmann, H. M. R.; Ismail, Z. M.; Hollweg, R.; Zein, A. R. Bull. Chem. Soc. Jpn. 1990, 63, 1807. doi:10.1246/bcsj.63.1807

28. Okimoto, M.; Chiba, T. Synthesis 1996, 1188. doi:10.1055/s-1996-4361

29. Baeza, A.; Nájera, C.; de Garcia Retamosa, M.; Sansano, J. M. Synthesis 2005, 2787. doi:10.1055/s-2005-872096

30. Bowry, V. W.; Ingold, K. U. J. Am. Chem. Soc. 1991, 113, 5699. doi:10.1021/ja00015a025

31. Newcomb, M. Tetrahedron 1993, 49, 1151. doi:10.1016/S0040-4020(01)85808-7

32. Suga, S.; Yamada, D.; Yoshida, J.-i. Chem. Lett. 2010, 39, 404. doi:10.1246/cl.2010.404

33. Yoshida, J.-i.; Saito, K.; Nokami, T.; Nagaki, A. Synlett 2011, 1189. doi:10.1055/s-0030-1259946

34. Khan, N. H.; Agrawal, S.; Kureshy, R. I.; Abdi, S. H. R.; Sadhukhan, A.; Pillai, R. S.; Bajaj, H. C. Catal. Commun. 2010, 11, 907. doi:10.1016/j.catcom.2010.04.005

\section{License and Terms}

This is an Open Access article under the terms of the Creative Commons Attribution License

(http://creativecommons.org/licenses/by/2.0), which permits unrestricted use, distribution, and reproduction in any medium, provided the original work is properly cited.

The license is subject to the Beilstein Journal of Organic Chemistry terms and conditions:

(http://www.beilstein-journals.org/bjoc)

The definitive version of this article is the electronic one which can be found at: doi:10.3762/bjoc. 10.12 